\title{
Måling av narkosedybde
}

\author{
Sammendrag \\ Bakgrunn. De siste 10-20 år har det \\ skjedd gjennombrudd i forståelsen av \\ anestesimedikamentenes effekter, og \\ det har kommet metoder for å kvantifi- \\ sere disse.
}

Materiale og metode. Denne oversikten er basert på et skjønnsmessig utvalg av litteratur fra siste 15 år, foredrag holdt av forfatteren og omarbeidede deler av hennes doktoravhandling.

Resultater. Narkose kan betraktes som en kombinasjon av søvn, analgesi og muskelavslapning. Moderne anestesimedikamenter er spesifikt rettet mot disse effektene. Farmakologisk variasjon gjør det umulig å fastsette en dose som passer alle, og det er derfor ønskelig å kvantifisere medikamenteffekter hos den enkelte pasient. Monitorer for søvndybde og dels for analgesi er kommersielt tilgjengelige. Av disse er bispektral indeks (BIS), som er basert på EEG, den best dokumenterte. Studier har vist at bruk av BIS-monitorering kan hindre både utilsiktet våkenhet og uønsket overdosering, men teknologien har også begrensninger. Det blir stadig diskutert hvilken plass slik teknologi skal ha i klinisk praksis.

Fortolkning. Selv om BIS-teknologien har vist seg lovende og er i utstrakt bruk, er det ikke i noe land anbefalt fra myndighetene at slikt utstyr skal være obligatorisk ved generell anestesi. Det tilrådes at bruken vurderes individuelt. Ut fra foreliggende dokumentasjon synes denne tilnærmingen foreløpig fornuftig også i Norge.
Siv Cathrine Høymork*

s.c.hoymork@medisin.uio.no

Anestesi- og intensivavdelingen

Vestre Viken, Sykehuset Asker og Bærum 1309 Rud

* Nåværende adresse:
Medisinsk fagavdeling
Den norske legeforening

Mer enn 160 år etter at den første narkosen for et kirurgisk inngrep ble gitt, er den eksakte definisjonen av «narkose» eller «generell anestesi» stadig under debatt (1). Rent praktisk kan narkose betraktes som en kombinasjon av søvn, analgesi og muskelrelaksasjon (fig 1). «Analgesi» brukes i denne sammenheng upresist, idet en ubevisst pasient ikke opplever smerte og dermed heller ikke smertelindring. Begrepet «nocisepsjon» betegner mer presist den fysiologiske stressresponsen på smerteutløsende stimuli hos ikke-bevisste pasienter.

Pasienten, anestesiologen og kirurgen vektlegger gjerne de enkelte delmålene for narkosen ulikt. Pasienten er vanligvis mest opptatt av hvorvidt han kommer til å sove under inngrepet og våkne opp etterpå. Kirurgen har sine primære krav knyttet til at pasienten skal ligge i ro og muskulaturen være tilstrekkelig avslappet til at operasjonen kan utføres trygt og presist. Anestesiologen vil trolig legge mest vekt på å balansere intensiteten av smertestimuli mot den farmakologiske demping av stressresponser, slik at pasienten verken opplever smerte eller utsettes for uønskede hemodynamiske svingninger (2).

De siste $10-15$ år har man fătt tilgang til nye, kortvirkende anestesimedikamenter med raskere anslag, som gjør det mulig å variere effekten etter den enkelte pasients behov i ulike faser av operasjonen. Slik titrering forutsetter imidlertid at medikamenteffekten kan måles. Derfor er kommersielle monitorer for å kvantifisere anestesieffekter blitt lansert. I denne artikkelen gis en kortfattet oversikt over prinsippene for monitorering av ulike anestesieffekter. Dessuten diskuteres hvilken plass slikt monitoreringsutstyr skal ha i klinikken.

\section{Materiale og metode}

Artikkelen er basert på et skjønnsmessig utvalg av litteratur fra de siste 15 år, forfatterens foredrag og deler av hennes doktoravhandling.

\section{Farmakologisk variasjon}

Responsen på et legemiddel varierer mellom individer, og ulike individer trenger ulik dose for å oppnå samme effekt. Dels beror dette på at en gitt dose fører til forskjellig serumkonsentrasjon, såkalt farmakokinetisk variasjon. Dels skyldes det at en gitt serumkonsentrasjon har varierende grad av effekt, såkalt farmakodynamisk variasjon.

I farmakologiske studier kan man måle hvilken konsentrasjon som gir en definert respons hos en bestemt andel pasienter. Eksempelvis vil EC50 (effektiv konsentrasjon50) beskrive den konsentrasjonen av et intravenøst legemiddel som sikrer at halvparten av pasientene får en bestemt respons. Begrepet «minste alveolære konsentrasjon» (MAC) er grunnleggende i anestesiologien (3). Det betegner den endetidale konsentrasjonen av en anestesigass som sikrer at $50 \%$ av pasientene $i$ en gitt alder ikke reagerer med motorisk avverging på abdominal incisjon (fig 2). Kunnskap om behovet $i$ en gruppe pasienter hjelper oss likevel bare i begrenset grad til å velge passende dose til den enkelte.

\section{Gassbaserte anestesimidler}

Om en potent anestesigass brukes alene, vil den konsentrasjonen som kreves for å blokkere stressresponsen ved det kirurgiske traumet, være rundt tre ganger så høy som den konsentrasjonen som trengs for å sikre søvn (fig 2). Konsentrasjon-respons-kurven for anestesigassenes effekter er dessuten bratt, hvilket illustrerer at den interindividuelle variasjonen i behovet er moderat.

En konsentrasjon på 1,4 MAC er tilstrekkelig for å sikre at andelen pasienter som oppnår en gitt effekt, øker fra $50 \%$ til 95\%. Dette tilsvarer klinisk relevante konsentrasjoner. En pasient som ikke frembyr kliniske tegn på utilfredsstillende analgesi under kirurgi når han bedøves med gass alene, kan

\section{Hovedbudskap}

- Utilsiktet våkenhet under narkose «awareness» - forekommer i om lag $0,1-0,2 \%$ av tilfellene

- Nye monitorer er utviklet for å kunne måle søvndybden under narkose

- Slike monitorer kan være til hjelp for individuell dosering, men de har også svakheter. Deres plass i klinisk praksis er ikke avklart 


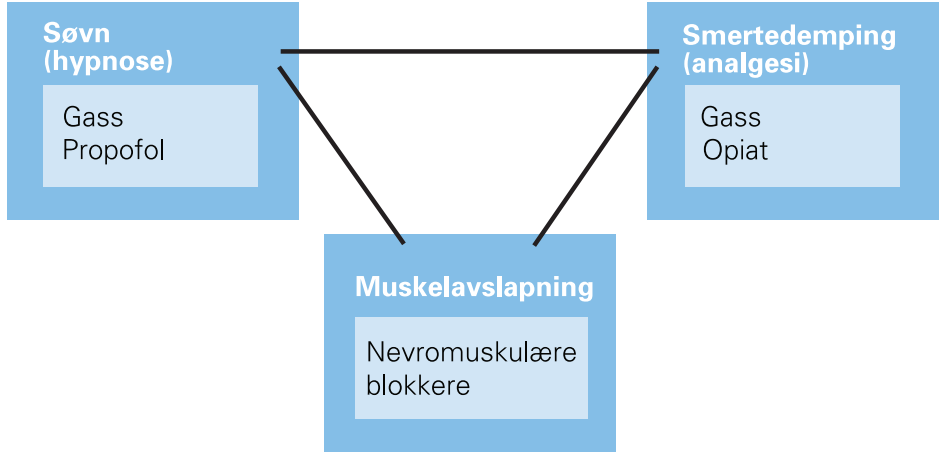

Figur 1 Legemidlene som benyttes under narkose, har ulike siktemål. Nevromuskulære blokkere gir muskelrelaksasjon, anestesigassene sikrer både søvn og analgesi. Opiater er hovedsakelig a betrakte som rene analgetika, som kombineres enten med intravenøse sovemidler eller med en lavdosert anestesigass for å sikre søvn derfor nærmest med sikkerhet forusettes å sove. Imidlertid kombineres oftest anestesigassene med opiater, slik at fravær av tegn på stress ikke er noen garanti for at pasienten sover. I tillegg er kliniske tegn på stressrespons også påvirket av andre faktorer.

\section{Intravenøse anestesimidler}

Mens potente anestesigasser gir både søvn og analgesi, sikter moderne intravenøse anestesimidler mot hver av de ønskede narkoseeffektene individuelt (fig 1), selv om rikelig overlapping og synergieffekt finnes (4). For intravenøs anestesi er propofol nærmest det eneste som i dag brukes for å vedlikeholde søvn. Propofol doseres som regel slik at konsentrasjonen ligger omkring eller sågar i underkant av EC50 (søvn), som for propofol er om lag $3 \mu \mathrm{g} / \mathrm{ml}(5,6)$.
Analgetisk medikasjon gis normalt i form av et opioid (fentanyl, remifentanil eller alfentanil). Opioider har sederende egenskaper i tillegg til den kraftige analgetiske effekten, men gitt alene vil et opioid ikke sikre søvn hos alle - selv i svært høye doser. Synergieffekter mellom propofol og opiat gjør at langt de fleste sover også under totalintravenøs anestesi, selv om dosen av det enkelte medikament alene kan synes snau.

\section{Nevromuskulære blokkere}

I noen tilfeller vil det være nødvendig å legge til et medikament som spesifikt lammer skjelettmuskulaturen perifert ved å blokkere nevromuskulær transmisjon. Det kan være ved inngrep der store muskelgrupper er involvert (f.eks. laparotomi), eller i tilfeller der bare en ørliten bevegelse vil kunne ha alvorlige følger (f.eks. øyekirurgi, nevrokirurgiske inngrep). Ofte gis også nevromuskulære blokkere rutinemessig for å lamme larynxmuskulaturen før intubasjon.

Generelt har nevromuskulære blokkere uforutsigbar virketid. Eventuelle resteffekter av disse medikamentene postoperativt er assosiert med betydelig fare for mikroaspirasjon og hypoventilasjon, med blant annet lungekomplikasjoner til følge. Det er derfor viktig å sikre at den nevromuskulær blokaden er opphørt innen pasienten skal overta ventilasjonen og opprettholde frie luftveier selv.

\section{Måling av medikamenteffekter}

Nevromuskulære blokkere

For å kunne kvantifisere grad av muskelblokade finnes det såkalte TOF-monitorer (train-of-four-monitorer), som kvantifiserer responsen fra en gitt muskelgruppe når man stimulerer den aktuelle nerven med strøm. Slike monitorer er ansett som pålitelige og anvendelige, og det blir anbefalt at man alltid benytter en slik dersom det gis nevromuskulære blokkere under narkosen (7).

\section{Analgetika}

Våkne pasienter vil normalt fremvise en motorisk avvergingsreaksjon ved smertefull stimulering. Evnen til å trekke seg unna smerten vil imidlertid ofte være hemmet under narkose pga. nevromuskulært blokkerende medikamenter og er dessuten ikke greit kvantifiserbar. Dertil ville det være uhensiktsmessig for kirurgen om bevegelser fra pasienten skulle styre tilførselen av narkosemedikamentene. I stedet anvendes normalt hemodynamisk og autonom respons som uttrykk for grad av analgesi - stiger pulsen eller blodtrykket, pupillene utvider seg eller pasienten blir svett, oppfattes det som uttrykk for at vedkommende behøver mer analgetika. Imidlertid er slike kliniske tegn usikre, idet de også kan være uttrykk for andre effekter. Eksempelvis kan pulsstigning uttrykke hypovolemi, pupilldilatasjon kan skyldes atropin, svette kan skyldes temperaturendringer.

Monitorer som skal kvantifisere analgesi og nocicepsjon ved hjelp av hemodynamiske tegn og andre fysiologiske responser er under utvikling. Blant annet finnes det et norsk apparat, StressDetector (MedstormInnovation), som måler hudens evne til å lede strøm. I den finske Surgical Pleth Index (GE Healthcare) brukes en kombinasjon av hemodynamiske data. I retrospektive studier har man funnet at begge instrumentene korrelerer med andre stressvariabler og med definerte smertefulle hendelser både per- og postoperativt $(8-12)$, men til nå er ingen av disse smertemonitorene blitt testet som anvendbare styringsverktøy under narkose (2).

Figur 2 Figuren viser respons på forskjellige stimuli avhengig av narkosegasskonsentrasjon. Konsentrasjon-effekt-kurvene for anestesigasser er avhengige av hvilken effekt man studerer. Det kreves høyere konsentrasjon av anestesigass for å blokkere respons på smertefull kirurgisk stimulering og intubasjon enn for å sikre søvn. Evnen til eksplisitt hukommelse svekkes allerede når konsentrasjonen av anestesimidler er så lav at den knapt gir klinisk observerbar sedasjon

\section{Sovemidler}

Under narkoseinnledningen defineres innsoving som det tidspunktet da pasienten ikke 
lenger responderer på verbal eller mild taktil stimulering. Under narkosen vil pasienten imidlertid ikke kunne gi uttrykk for om han fortsatt sover, især ikke om det er tilført nevromuskulære blokkere. Kliniske tegn kan heller ikke med særlig grad av pålitelighet uttrykke om og i hvilken grad pasienten er tilført mer sovemiddel enn nødvendig. En rekke studier har vist at hemodynamiske variabler kan være helt stabile også hos dem som er utilsiktet våkne $(13,14)$.

For bedre å kunne styre tilførselen av sovemiddel under anestesi har man derfor lett etter monitoreringsprinsipper basert på surrogatendepunkter. Selv om flere fysiologiske responser har vært forsøkt benyttet til kvantifisering av søvndybde (15), har elektroenecefalogram (EEG) vært mest studert. EEG påvirkes ulikt av ulike anestesimidler, men generelt vil regelmessigheten tilta ved økende anestesidybde, samtidig som amplituden øker og frekvensen faller. Informasjonsmengden i et ubearbeidet EEG gjør det uegnet som beslutningsgrunnlag for fortløpende justeringer under narkose. Ved hjelp av «power»- og spektralanalyser av EEG kan man imidlertid kvantifisere effekter av anestesimidler på den cerebrale elektriske aktiviteten og derigjennom få informasjon om anestesidybden (16).

\section{Bispektral indeks}

for monitorering av anestesieffekt

Bispektral indeks (BIS) (Aspect Medical) ble lansert i midten av 1990-årene (17). BISmetoden innbefatter «power»- og spektralanalysene og bispektral analyse av EEGbølgene. En bispektral analyse går ut fra havbølgeteorier og kan kort forklares slik at man studerer hvordan én sinusbølge påvirker den neste (18). Selv om hovedtrekkene i algoritmen for beregning av bispektral indeks er publisert, er en liten del stadig en beskyttet bedriftshemmelighet, hvilket ofte holdes frem som et argument mot anvendelsen (19).

En BIS-monitor er enten frittstående eller kan integreres i de fleste overvåkingsenheter. Pasienten kobles til apparatet ved hjelp av klistrelappelektroder i panneregionen. Den bispektrale indeksen oppgis som et tall mellom 0 og 100, der verdier over 95 er typiske for en helt våken person og verdier ned mot 0 uttrykker isolelektrisk EEG og dermed opphør av cerebral aktivitet (f.eks. ved meget dyp anestesi, grav hypotermi eller opphørt hjernesirkulasjon). For kirurgisk anestesi sikter man vanligvis mot BIS-verdier mellom 40 og 60 (fig 3) (20).

I tidlige studier fant man god korrelasjon mellom BIS-verdier og klinisk vurdert sedasjonsnivå, hukommelse og evne til innlæring, men dårligere samsvar mellom verdiene og smertefull stimulering (21-27). Omtrent samtidig ble det gjort studier som førte til endret oppfatning av mer basale anestesimekanismer. Ira Rampil studerte behovet for anestestika hos rotter med artifisielt fremkalte tverrsnittslesjoner (28) og decerebrerte rotter (29). Joseph Antognini studerte en geitemodell der sirkulasjonen til hhv. hjerne og ryggmarg ble skilt ved at man underbandt halsarterier og forsørget den cerebrale sirkulasjonen ved hjelp av hjertelunge-maskin. Derigjennom kunne man tilføre ulike konsentrasjoner av anestetika samtidig til forskjellige avsnitt av sentralnervesystemet (30). Disse dyrestudiene viste at anestetika hemmer motoriske avvergingsreaksjoner på smerte hovedsakelig ved virkning på ryggmargsnivå og at effekten bare $\mathrm{i}$ liten grad skyldes midlenes effekter på cerebral aktivitet - det som man ved hjelp av BIS-metoden tok sikte på å kvantifisere.

I andre typer studier ble pasientene randomisert til enten å få narkosemidlene justert etter BIS-verdier eller etter alminnelige kliniske variabler som hemodynamikk, pupillstørrelse etc. De som ble styrt etter BIS-metoden, våknet raskere og/eller ble tilført mindre doser narkosemidler, og dette gjaldt både for gassanestesi og intravenøs anestesi $(31,32)$. Median oppvåkningstid ble ikke påvirket i særlig grad, men blant de BISstyrte pasientene forsvant «sjusoverne» (de som har en vesentlig forlenget oppvåkningstid), sannsynligvis fordi de har et vesentlig lavere behov for anestesimiddel enn gjennomsnittspasienten. Imidlertid konkluderte en metaanalyse fra 2004 med at det var en negativ kostnad-nytte-effekt, idet kostnadene ved BIS-monitorering ikke ble oppveid av innsparte medikamentutgifter, redusert liggetid og lavere forekomst av postoperativ kvalme (33). En BIS-monitor koster i dag om lag kr 30000 , elektroder til én pasient $i$ underkant av kr 100 (Rune Strand, Infiniti Medical, personlig meddelse).

\section{Utilsiktet våkenhet - «awareness»}

Studier der man påviste hvordan BIS-monitorering kunne hindre utilsiktet våkenhet under narkose (awareness), ble først publisert ti år etter at monitoren kom på markedet (34, 35). Dette skyldes at fenomenet heldigvis er sjeldent forekommende - de tre seneste kartlegginger av forekomst $i$ vestlige materialer konkluderte med at det opptrer ved om lag $0,1-0,2 \%$ av alle narkoser (36-38). Riktignok finnes det en nyere studie der det fremheves at fenomenet er enda sjeldnere $(0,007 \%)$ (39), men i denne studien er det noen metodologiske problemer, især med identifikasjon av tilfellene av utilsiktet våkenhet.

Det finnes ingen randomiserte studier ved ikke-selekterte kirurgiske inngrep der man sammenlikner forekomst av utilsiktet våkenhet med og uten bruk av BIS-monitorering. Imidlertid er det en studie med pasienter der selve den kirurgiske prosedyren (keisersnitt, traume, åpen hjertekirurgi og stiv bronkoskopi) er forbundet med betydelig $ø k t$ forekomst av fenomenet (1\%). 1225 pasienter ble randomisert til å få narkosen styrt etter BIS-monitorering, mens man hos 1238 kontrollpasienter styrte etter kliniske variabler. Sikker utilsiktet våkenhet ble påvist hos 11 i kontrollgruppen ( $1 \%$, som forventet), mot hos to i BIS-gruppen $(0,2 \%), \mathrm{p}<0,05$ (35). I en svensk studie ble 5000 BIS-monitorerte sammenliknet med 7800 ikke-monitorerte historiske pasienter (34). Forekomsten av utilsiktet våkenhet ble redusert fra $0,2 \%$ til $0,04 \%$.

I en nyere amerikansk randomisert studie finner man imidlertid ingen «awareness»reduserende effekt av BIS-styring (40). Meget prisverdig er denne studien gjennomført helt uten industristøtte. Betenkeligheter med produsentstøttet forskning innenfor dette feltet er drøftet $\mathrm{i}$ en ledsagende lederartikkel (41). Et hovedproblem i tolkingen av den amerikanske studien er imidlertid at kontrollgruppen ble tilført større doser anestesimiddel enn vanlig klinisk praksis skulle tilsi. En rekke andre særegenheter, blant annet knyttet til inklusjonskriteriene, er også blitt kritisert i en lederartikkel (42).

\section{BIS-verdier og mortalitet}

Det er vist at lave peroperative BIS-verdier er korrelert med økt ettårsmortalitet etter kirurgiske inngrep. I en studie med 1300 pasienter ble det vist at for hver time BISverdiene var $<45$, var risikoen for å dø det neste året økt med $24 \%$ (43). Dette funnet er støttet i retrospektive analyser av de 5000 pasientene som inngikk i den omtalte svenske studien om utilsiktet våkenhet (34). Dyp anestesi var i begge disse studiene en selvstendig og uavhengig prediktor for $ø \mathrm{kt}$ mortalitet. Imidlertid fant man at $75 \%$ av alle dødsfallene i det svenske materialet innenfor første postoperative år skyldtes disseminert kreft (44). Sammenhengen er dermed sannsynligvis slik at pasienter som det viser seg har hatt avansert kreftsykdom på operasjonstidspunktet, blir kraftigere påvirket av en «normal» dose anestesimiddel.

\section{Andre søvndybdemonitorer}

Flere konkurrenter til BIS-monitoren er kommet på markedet. I Norge selges for tiden tre andre: Entropy (GE HealthCare), AEP II-monitor og Cerebral State Monitor (CSM) (Danmeter). Entropy- og CSM-monitorene er basert på ustimulert EEG, som bearbeides til en indeks på mellom 0 og 100 (kirurgisk anestesi er angitt å ligge mellom 40 og 60) (45-48). Algoritmene skiller seg fra BIS-metoden og fra hverandre. AEP IImonitor bruker foruten spontant EEG også stimulert elektrisk aktivitet fra 8. hjernenerve. Pasientene har påsatt øreplugger, hvorfra det kommer en jevn høyfrekvent klikkelyd. AEP-indeksen er også skalert fra 0 til 100, men der er kirurgisk anestesidydbe anført å ligge mellom 15 og 25 .

Det er ingen enighet om hvilken av søvnmonitorene som er best eller hvilke kriterier som skal legges til grunn for sammenlikning. BIS-monitorering er klart best dokumentert, i over 1000 originalartikler (49). 


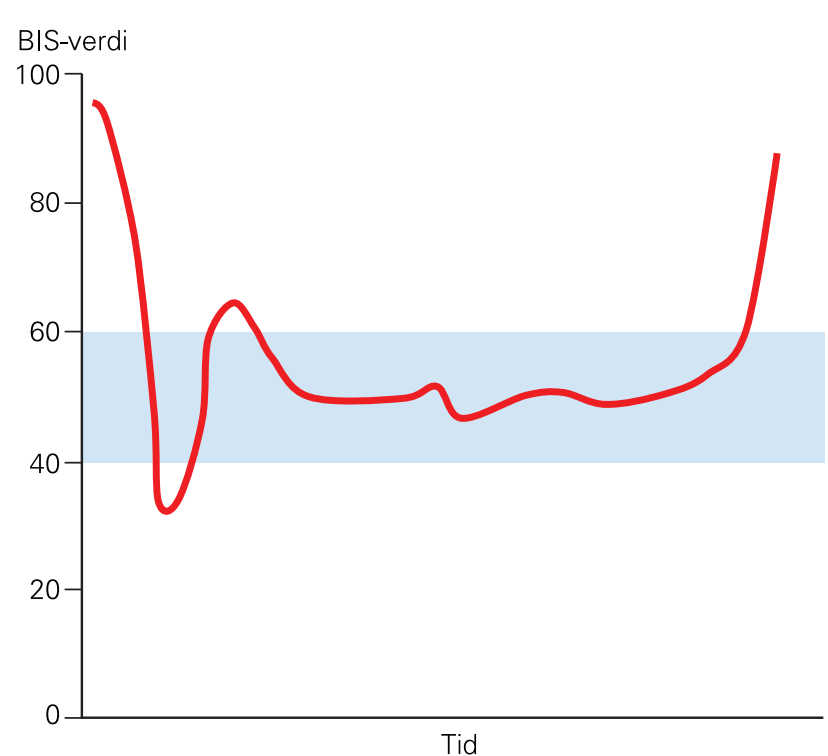

Figur 3 Figuren viser et typisk forløp av trendkurven for bispektral indeks (BIS) under en ukomplisert narkose. På y-aksen vises BIS som enhetsløse verdier mellom 0 og 100, mens x-aksen viser tiden. En BIS-verdi på 100 er uttrykk for helt våken pasient, mens verdier i området 40-60 er normale under kirurgi. Etter intubasjonen, som representerer en meget kraftig stimulus, ses ofte en kortvarig topp

Også tidsforsinkelsen varierer monitorene imellom, og den avviker dels betydelig fra det produsentene angir (50). Man opplever også situasjoner der ulike monitorer gir meget ulike resultater (51). I mangel av myndighetskrav til dokumentasjon av nytte av medisinskteknisk utstyr vil man kunne forvente tallrike fremtidige konkurrenter markedsført nærmest uten vitenskapelig dokumentasjon.

\section{Retningslinjer}

\section{for søvndybdemonitorer}

En Cochrane-analyse konkluderer med at bruk av BIS-monitorering har en signifikant innvirkning både på forekomst av utilsiktet våkenhet og på oppvåkningsvariabler (52). Det amerikanske akkrediteringsselskapet for helsepersonell (JCAHO), Food and Drug Administration (FDA) og den amerikanske anestesilegeforeningen (ASA) har uttalt at bruk av BIS-monitor kan hindre tilfeller av utilsiktet våkenhet, men man har ikke funnet det riktig å anbefale at slik monitorering skal være obligatorisk (53). Andre lands helsemyndigheter, som systematisk har vurdert dette spørsmålet, har heller ikke valgt å stille krav til rutinemessig bruk av søvndybdemonitorering. Dels er dette begrunnet i kostnadnytte-analyser. Dertil kommer stadige problemer med teknologien, blant annet påvirkning fra ytre elektriske kilder (som diatermi), påvirkning av annen medikasjon (som lystgass, ketamin, vasopressorer), fortolkning av EMG og tallrike rapporter om avvikende avlesninger hos enkeltpasienter (54).

Det foreligger ingen undersøkelser om utbredelse eller bruk av søvndybdemonitorer
Norge. Det er et inntrykk at de fleste avdelinger har i hvert fall én monitor til bruk hos selekterte pasienter.

\section{Oppsummering \\ og fremtidsperspektiver}

Generell anestesi eller narkose skal sikre søvn og dempe stressresponser og muskelaktivitet. Moderne anestesimidler sikter dels mot hver av disse effektene separat. De siste 10-15 år har det kommet monitorer for styring av sovemiddeltilførsel under narkose. Det arbeides med å ta slike i bruk for medikamenttilførsel i mer automatiserte systemer («closed-loop») eller autopilotanestesi) (55-57).

Oppgitte interessekonflikter: Forfatteren har lånt søvndybdemonitorer fra de tre firmaene som leverer slike i Norge - AspectMedical, GE Healthcare og Danmeter - til sin forskning og har mottatt gratis elektroder til klinisk forskning. Videre har hun mottatt honorar for foredrag og støtte til kongressreiser fra GlaxoSmithKline, som er norsk forhandler av søvndybdemonitoren CSM.

\section{Litteratur}

1. Eger EI, Sonner JM. Anaesthesia defined Igentlemen, this is no humbug). Best Pract Res Clin Anaesthesiol 2006; 20: 23-9.

2. Hoymork SC. Antinociceptive monitors: tools or fools? Acta Anaesthesiol Scand 2008; 52: 1035 -7.

3. Eger El, Saidman LJ, Brandstater B. Minimum alveolar anesthetic concentration: a standard of anesthetic potency. Anesthesiology 1965; 26: $756-63$

4. Hendrickx JF, Eger El, Sonner JM et al. Is synergy the rule? A review of anesthetic interactions producing hypnosis and immobility. Anesth Analg 2008; 107: 494-506.

5. Shafer A, Doze VA, Shafer SL et al. Pharmacokinetics and pharmacodynamics of propofol infusions during general-anesthesia. Anesthesiology 1988; 69: $348-56$

6. Kodaka M, Johansen JW, Sebel PS. The influence of gender on loss of consciousness with sevoflurane or propofol. Anesth Analg 2005. 101: 377-81.

7. Hemmerling TM, Le N. Brief review: Neuromuscular monitoring: an update for the clinician. Can J Anaesth 2007; 54: 58-72.

8. Storm H. Changes in skin conductance as a tool to monitor nociceptive stimulation and pain. Curr Opin Anesthesiology 2008; 21: 796-804

9. Storm H, Myre K, Rostrup M et al. Skin conductance correlates with perioperative stress. Acta Anaesthesiol Scand 2002: 46: 887-95.

10. Ledowski T, Bromilow J, Wu J et al. The assessment of postoperative pain by monitoring skin conductance: results of a prospective study. Anaesthesia 2007; 62: 989-93.

11. Huiku M, Uutela K, van Gils M et al. Assessment of surgical stress during general anaesthesia. $\mathrm{Br} J$ Anaesth 2007; 98: 447-55

12. Struys MM, Vanpeteghem C, Huiku M et al. Changes in a surgical stress index in response to standardized pain stimuli during propofol-remifentanil infusion. Br J Anaesth 2007; 99: 359-67.

13. Domino KB, Posner KL, Caplan RA, et al. Awareness during anesthesia: a closed claims analysis. Anesthesiology 1999: 90: 1053-61.

14. Moerman N, Bonke B, Oosting J. Awareness and recall during general anesthesia. Facts and feelings. Anesthesiology 1993; 79: 454-64.

15. Heier T, Steen PA. Assessment of anaesthesia depth. Acta Anaesthesiol Scand 1996; 40 . 1087-100.

16. Tonner PH, Bein B. Classic electroencephalographic parameters: median frequency, spectral edge frequency etc. Best Pract Res Clin Anaesthesiol 2006; 20: 147-59.

17. Sigl JC, Chamoun NG. An introduction to bispectral analysis for the electroencephalogram. J Clin Monit 1994: 10: 392-404.

18. Rampil IJ. A primer for EEG signal processing in anesthesia. Anesthesiology 1998; 89: 980-1002.

19. Bruhn J, Myles PS, Sneyd R et al. Depth of anaesthesia monitoring: what's available, what's validated and what's next? $\mathrm{Br} J$ Anaesth 2006; 97 : $85-94$

20. Johansen JW, Sebel PS. Development and clinica application of electroencephalographic bispectrum monitoring. Anesthesiology 2000; 93 : $1336-44$.

21. Sebel PS, Bowles SM, Saini V et al. EEG bispectrum predicts movement during thiopental/isoflurane anesthesia. J Clin Monit 1995; 11: 83-91.

22. Kearse LA, Manberg P. Chamoun N et al. Bispectral analysis of the electroencephalogram correlates with patient movement to skin incision during propofol/nitrous oxide anesthesia. Anesthesiology 1994: 81: 1365-70.

23. Gajraj RJ, Doi M, Mantzaridis $\mathrm{H}$ et al. Analysis of the EEG bispectrum, auditory evoked potentials and the EEG power spectrum during repeated transitions from consciousness to unconscious ness. Br J Anaesth 1998; 80: 46-52.

24. Glass PS, Bloom M, Kearse L et al. Bispectral analysis measures sedation and memory effects of propofol, midazolam, isoflurane, and alfentanil in healthy volunteers. Anesthesiology 1997; 86: 836-47.

25. Flaishon R, Windsor A, Sigl J et al. Recovery of consciousness after thiopental or propofol. Bispectral index and isolated forearm technique. Anesthesiology 1997; 86: 613-9.

26. Liu J, Singh H, White PF. Electroencephalographic bispectral index correlates with intraoperative recall and depth of propofol-induced sedation. Anesth Analg 1997; 84: 185-9.

27. Leslie K, Sessler DI, Schroeder M et al. Propofol blood concentration and the Bispectral Index predict suppression of learning during propofol/epidural anesthesia in volunteers. Anesth Analg 1995 81: $1269-74$

28. Rampil IJ. Anesthetic potency is not altered after hypothermic spinal cord transection in rats. Anesthesiology 1994; 80: 606-10.

29. Rampil IJ, Mason P. Singh H. Anesthetic potency (MAC) is independent of forebrain structures in the rat. Anesthesiology 1993; 78: 707-12. 
30. Antognini JF, Schwartz K. Exaggerated anesthetic requirements in the preferentially anesthetized brain. Anesthesiology 1993; 79: 1244-9.

31. Gan TJ, Glass PS, Windsor A et al. Bispectral index monitoring allows faster emergence and improved recovery from propofol, alfentanil, and nitrous oxide anesthesia. BIS Utility Study Group. Anesthesiology 1997; 87: 808-15.

32. Song D, Joshi GP. White PF. Titration of volatile anesthetics using bispectral index facilitates recovery after ambulatory anesthesia. Anesthesiology 1997; 87: 842-8.

33. Liu SS. Effects of bispectral index monitoring on ambulatory anesthesia - a meta-analysis of randomized controlled trials and a cost analysis. Anesthesiology 2004; 101: 311-5.

34. Ekman A, Lindholm ML, Lennmarken $C$ et al. Reduction in the incidence of awareness using BIS monitoring. Acta Anaesthesiol Scand 2004; 48 : $20-6$.

35. Myles PS, Leslie K, McNeil J et al. Bispectral index monitoring to prevent awareness during anaesthesia: the B-Aware randomised controlled trial. Lancet 2004; 363: 1757-63.

36. Myles PS, Williams DL, Hendrata M et al. Patient satisfaction after anaesthesia and surgery: results of a prospective survey of 10811 patients. $\mathrm{Br} \mathrm{J}$ Anaesth 2000; 84: 6-10.

37. Sandin RH, Enlund G, Samuelsson P et al. Awareness during anaesthesia: a prospective case study. Lancet 2000; 355: 707-11.

38. Sebel PS, Bowdle TA, Ghoneim MM et al. The incidence of awareness during anesthesia: a multicenter United States study. Anesth Analg 2004; 99: 833-9.

39. Pollard RJ, Coyle JP, Gilbert RL et al. Intraoperative awareness in a regional medical system: a review of 3 years' data. Anesthesiology 2007 106: $269-74$.
40. Avidan MS, Zhang L, Burnside BA et al. Anesthesia awareness and the bispectral index. N Engl J Med 2008; 358: 1097-108.

41. Orser BA. Depth-of-anesthesia monitor and the frequency of intraoperative awareness. $N$ Engl J Med 2008; 358: 1189-91.

42. Sneyd JR, Mathews DM. Memory and awareness during anaesthesia. Br J Anaesth 2008; 100: 742-4.

43. Monk TG, Saini V. Weldon BC et al. Anesthetic management and one-year mortality after noncardiac surgery. Anesth Analg 2005; 100: 4-10.

44. Lindholm ML, Träff S, Granath F et al. Mortality within two years after surgery in relation to low intraoperative BIS values and pre-existing malignant disease. Anesth Analg 2009; 108: 508-12.

45. Viertio-Oja H, Maja V, Sarkela M et al. Description of the entropy algorithm as applied in the DatexOhmeda S/5 Entropy Module. Acta Anaesthesiol Scand 2004: 48: 154-61.

46. Anderson RE, Jakobsson JG. Cerebral state monitor, a new small handheld EEG monitor for determining depth of anaesthesia: a clinical comparison with the bispectral index during day-surgery. Eur J Anaesthesiol 2006; 23: 208-12

47. Anderson RE, Jakobsson JG. Cerebral state index response to incision: a clinical study in day-surgical patients. Acta Anaesthesiol Scand 2006; 50: 749-53.

48. Vakkuri A, Yli-Hankala A, Talja P et al. Time-frequency balanced spectral entropy as a measure of anesthetic drug effect in central nervous system during sevoflurane, propofol, and thiopental anesthesia. Acta Anaesthesiol Scand 2004: 48 : $145-53$.

49. Johansen JW. Update on bispectral index monitoring. Best Pract Res Clin Anaesthesiol 2006; 20: $81-99$.

50. Pilge S, Zanner R, Schneider G et al. Time delay of index calculation: analysis of cerebral state, bispectral, and narcotrend indices. Anesthesiology 2006; 104: 488-94.

51. Hoymork SC, Hval K, Jensen EW et al. Can the cerebral state monitor replace the bispectral index in monitoring hypnotic effect during propofol/ remifentanil anaesthesia? Acta Anaesthesiol Scand 2007; 51: 210-6.

52. Punjasawadwong Y, Boonjeungmonkol N, Phongchiewboon A. Bispectral index for improving anaesthetic delivery and postoperative recovery. Cochrane Database Syst Rev 2007; CD003843.

53. Practice advisory for intraoperative awareness and brain function monitoring: a report by the american society of anesthesiologists task force on intraoperative awareness. Anesthesiology 2006; 104: 847-64

54. Dahaba AA. Different conditions that could result in the bispectral index indicating an incorrect hypnotic state. Anesth Analg 2005; 101: 765-73.

55. Struys MM, De ST, Versichelen LF et al. Comparison of closed-loop controlled administration of propofol using Bispectral Index as the controlled variable versus «standard practice» controlled administration. Anesthesiology 2001; 95: 6-17.

56. Absalom AR, Kenny GN. Closed-loop control of propofol anaesthesia using bispectral index: performance assessment in patients receiving computer-controlled propofol and manually controlled remifentanil infusions for minor surgery. $\mathrm{Br} J$ Anaesth 2003; 90: 737-41.

57. Struys MM, Mortier EP, De Smet T. Closed loops in anaesthesia. Best Pract Res Clin Anaesthesiol 2006; 20: 211-20.

Manuskriptet ble mottatt 19.10. 2008 og godkjent 20.5. 2009. Medisinsk redaktør Michael Bretthauer. 